\title{
EXPLORING PLATE TECTONICS WITH MODELS AND AN \\ ONLINE CURRICULUM
}

Kathryn M. Bateman

Penn State/Temple University

kathrynbateman@temple.edu

Amy Pallant

Trudi Lord

The Concord Consortium

apallant@concord.org

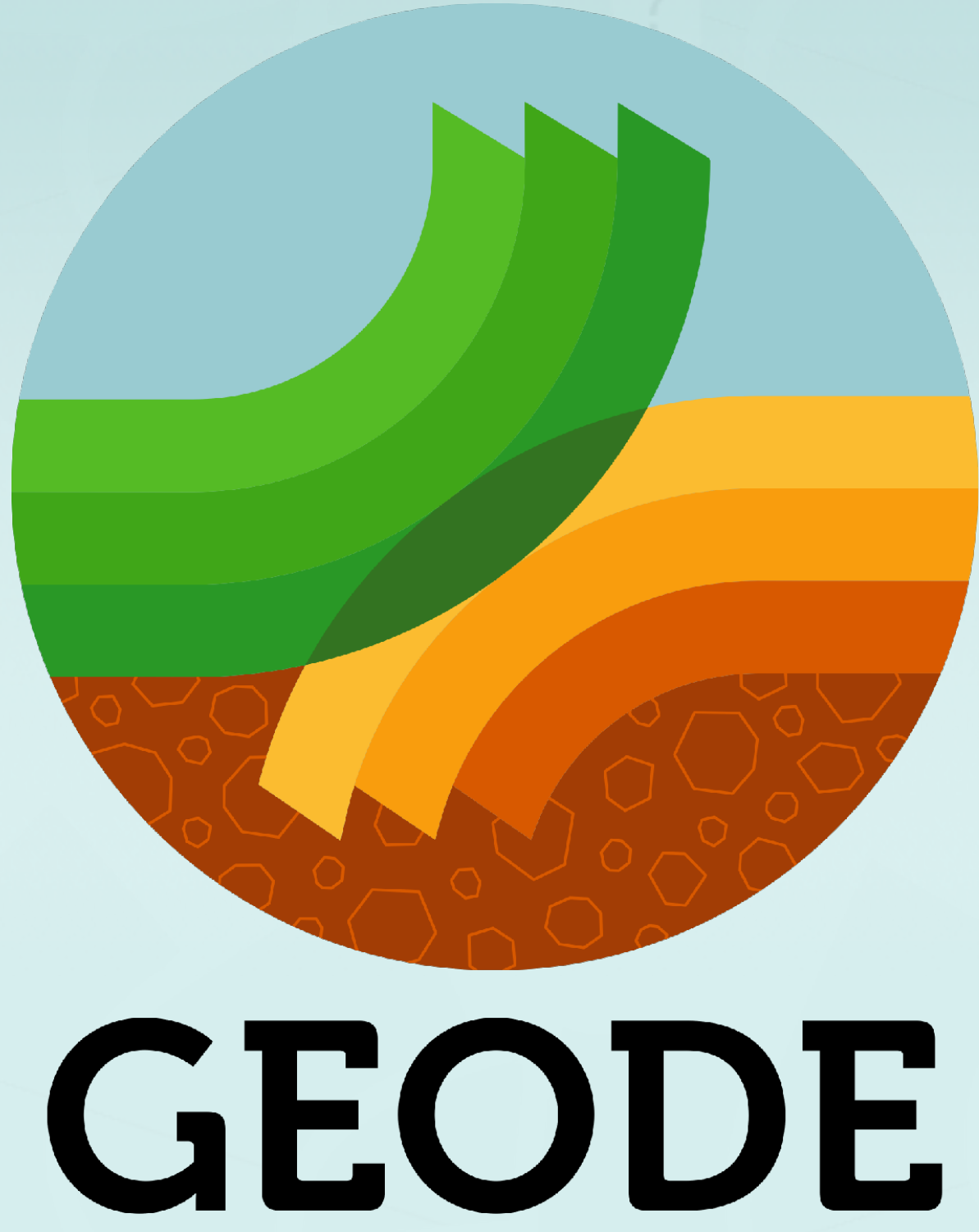

Scott McDonald

Penn State University smcdonald@psu.edu 
Time to Explore: Actively Engaging with Rigorous Three-Dimensional Learning Materials

EXPLORING PLATE TECTONICS WITH MODELS AND AN ONLINE CURRICULUM

In this presentation, the following questions will be addressed:

1. Why create online curriculum materials and models for students?

2. What supports are in place for online curriculum to support student learning of science?

3. What supports are in place to aide teachers in use of the online curriculum? 
Plate tectonics demands an understanding of complex, invisible, dynamic processes.

Experiments, as traditionally perceived of in $\mathrm{K}-12$ classrooms, are impossible.

The processes that shape the Earth take place out of sight, over unimaginably long times. This temporal scale challenges K-12 students understanding of the processes.

The processes of plate tectonics take places a part of an integral system, which challenges the spatial skills of students.

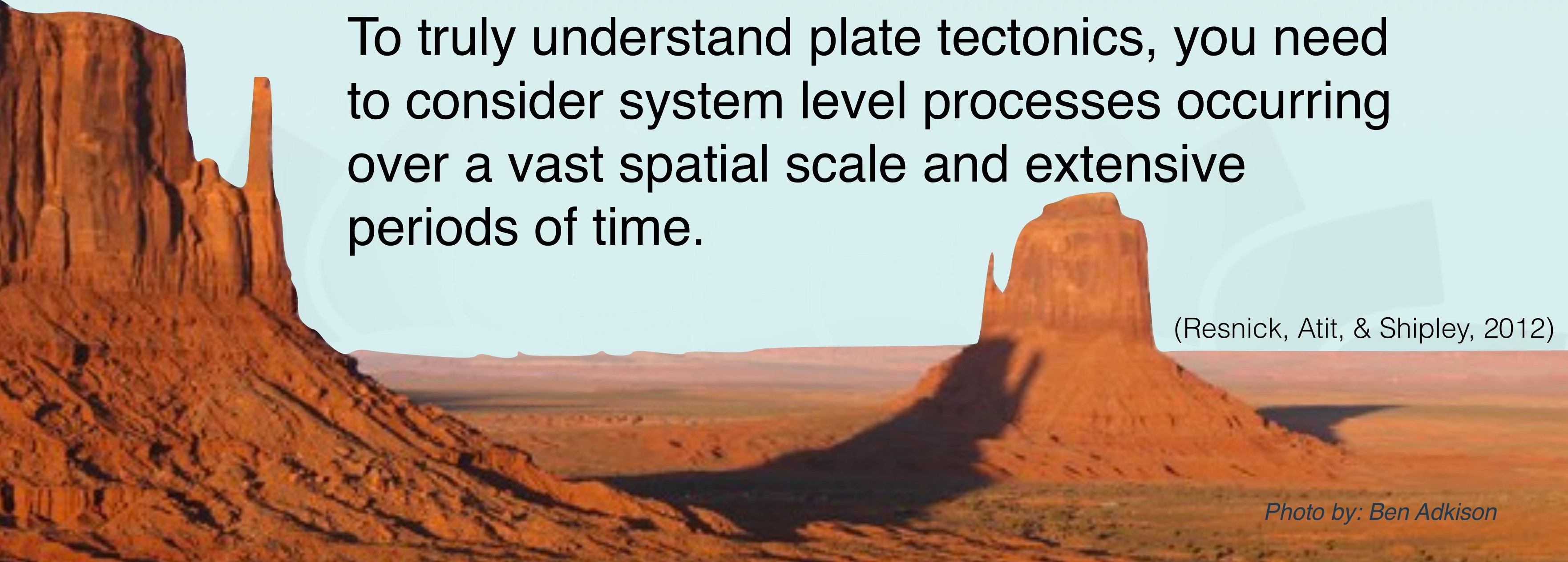




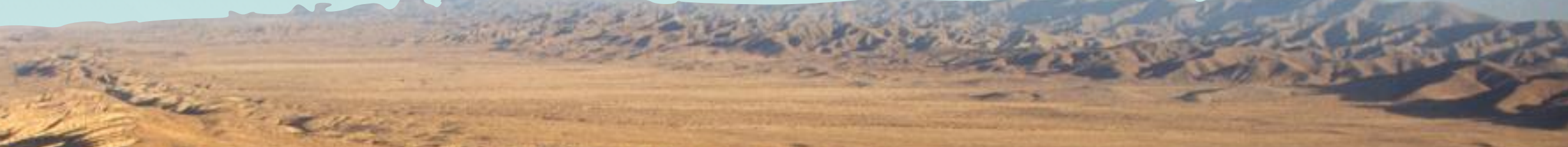

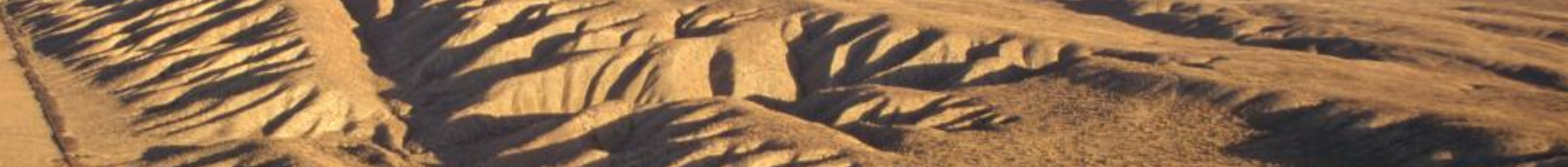

$$
\begin{aligned}
& \text { - }
\end{aligned}
$$

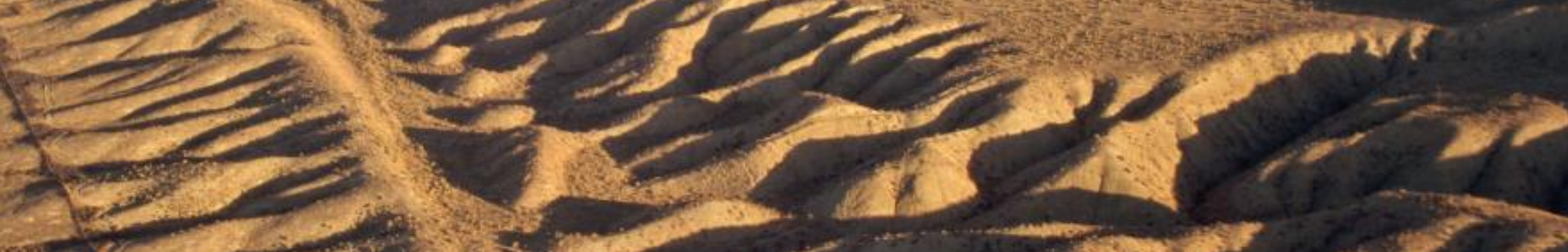

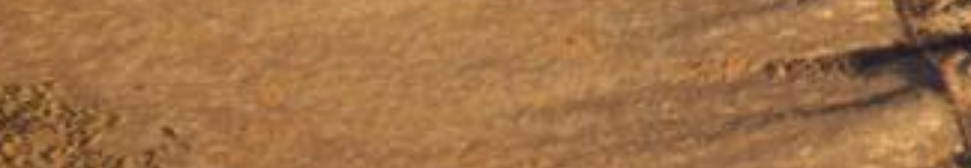




\section{Teaching Plate Tectonics}

The way plate tectonics is currently taught in secondary schools, students don't develop a system-level understanding.

Students need to understand plate tectonics as a dynamic system process of mantle convection causing plate to move with respect to each other beyond limited boundary-level understandings.

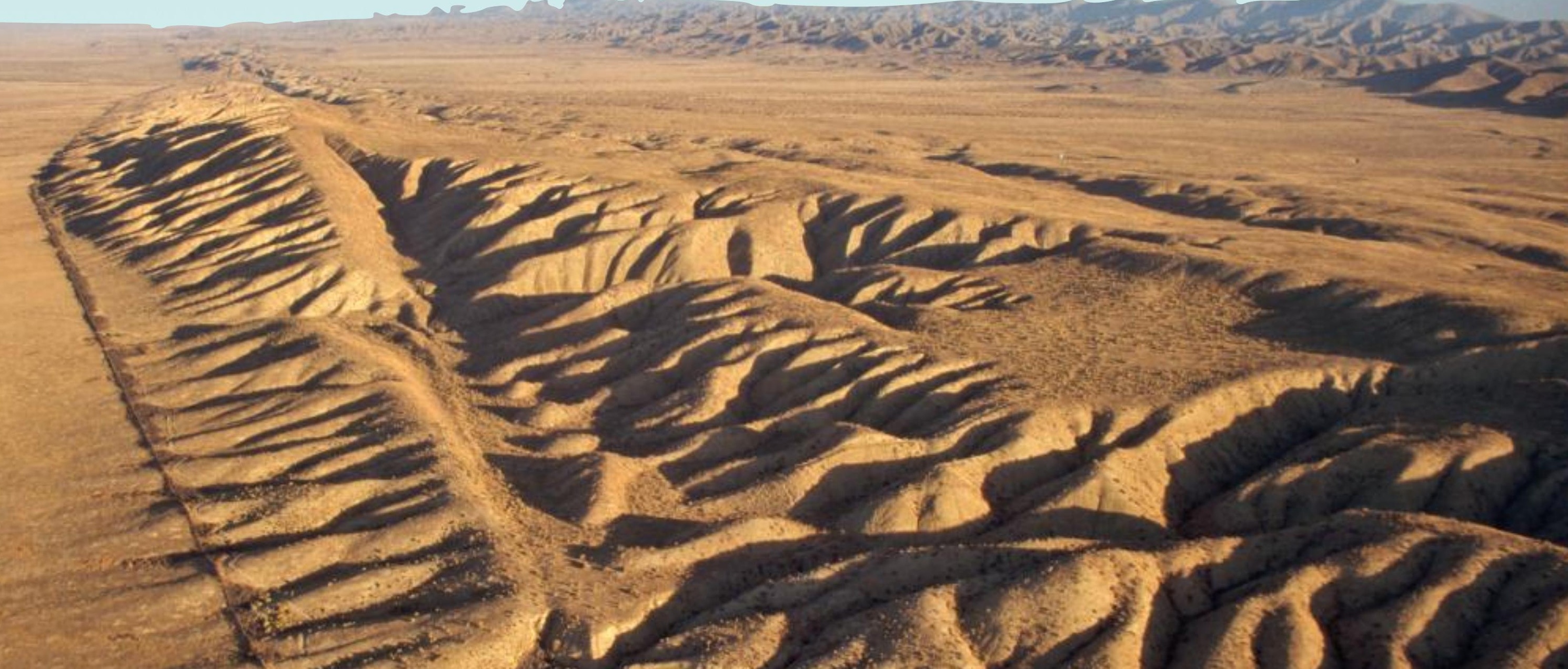




\section{The Challenges in Geoscience}

Geosciences, and plate tectonics in particular, needs to join the other sciences as an investigatory (lab) science - it needs to be about developing an understanding of the world via exploration of data, observations, and models. However, geoscience, because of its temporal and spatial scales, does not explore scientific questions in the same way as more traditional classroom sciences.

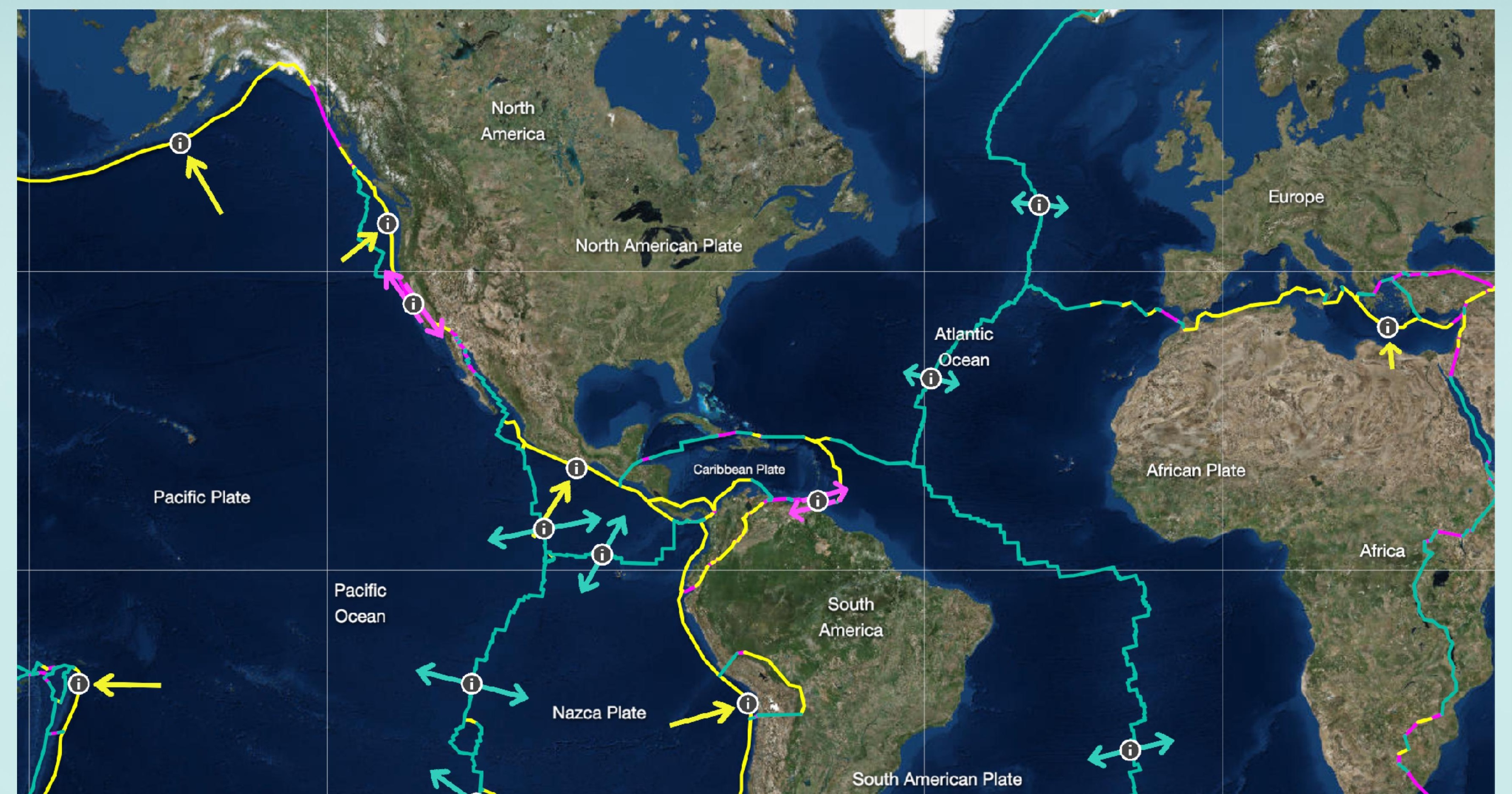




\section{The Next Generation Science Standards (NGSS)}

The NGSS provide states, districts, schools, and teachers with a framework for teaching science. At the Middle School level, students are expected to use historical data to explain plate motion. However, what this data looks like and the sources from which it comes are undefined.

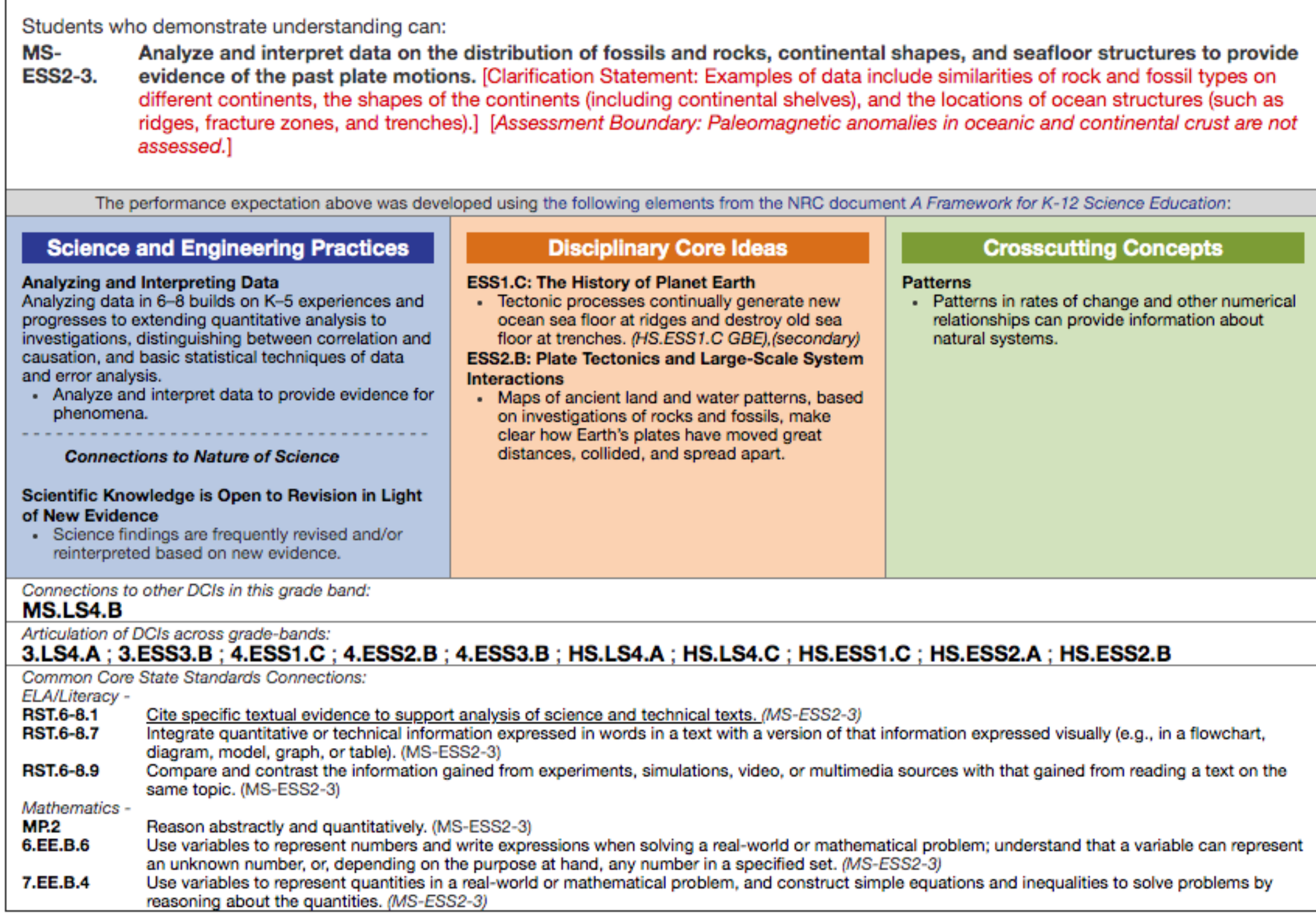




\section{The GEODE Model}

The GEODE curriculum is grounded in not only the NGSS but also in Ambitious Science Teaching (Windschitl, Thompson, \& Braaten, 2018) where a unit of investigation is driven by a phenomenon and students collect evidence to support an explanation of the phenomenon. Student talk, not often a part of online curricula is high encouraged in the model, and supported with tips in the teacher edition.
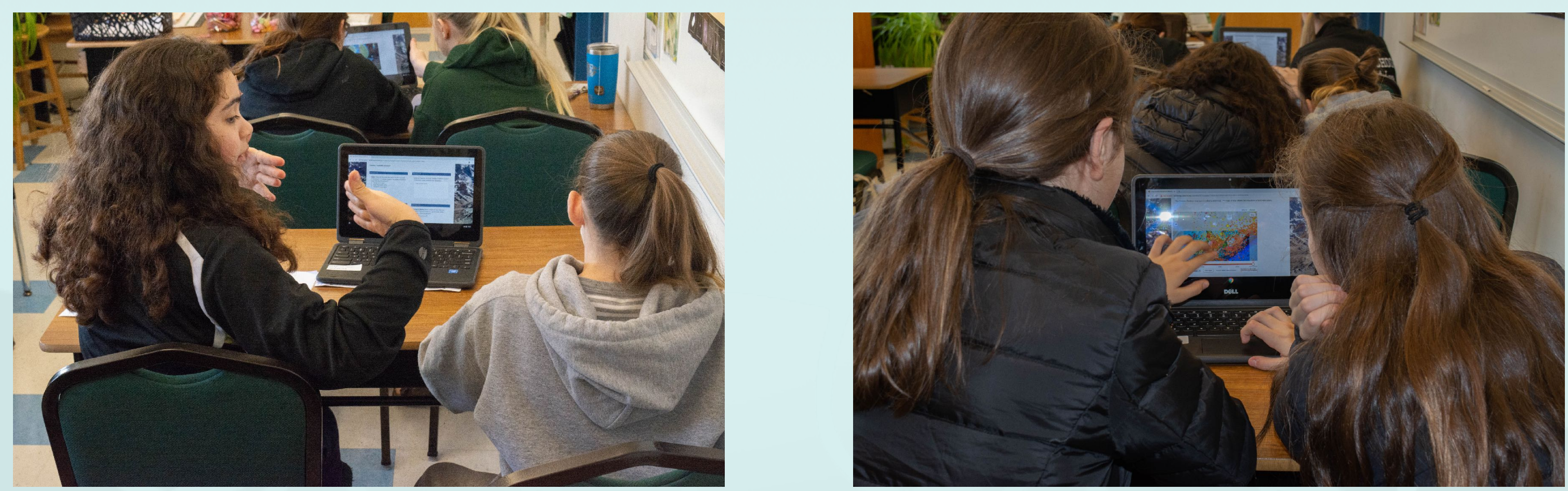


\section{The GEODE driving phenomenon: What will Earth look like in 500 million years?}

\section{crook What will Earth look like in $\mathbf{5 0 0}$ million} years?

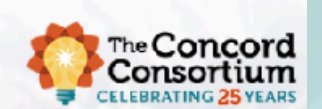

$\mathrm{Hi}$, apallant

In this module, you will consider the question: what will Earth look like in 500 million years? You will use data from Earth and models of a fictional planet to explore plate tectonics.

(1) Estimated Time to Complete This Module: 345 minutes

1 Earth's moving surface

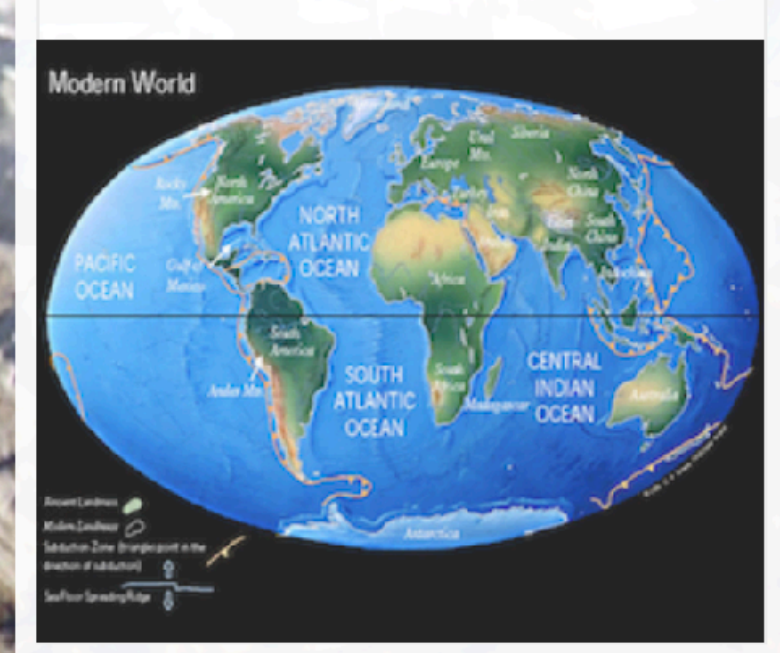

4 What drives plate motion?

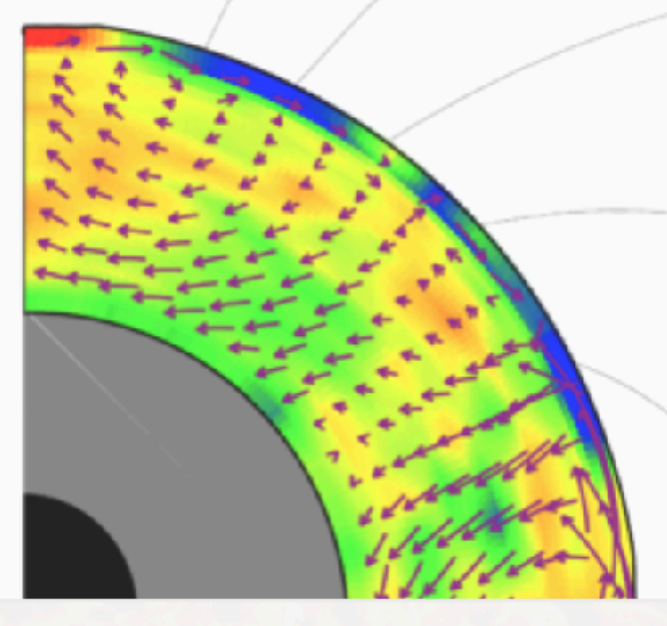

2 Interpreting Earth's clues

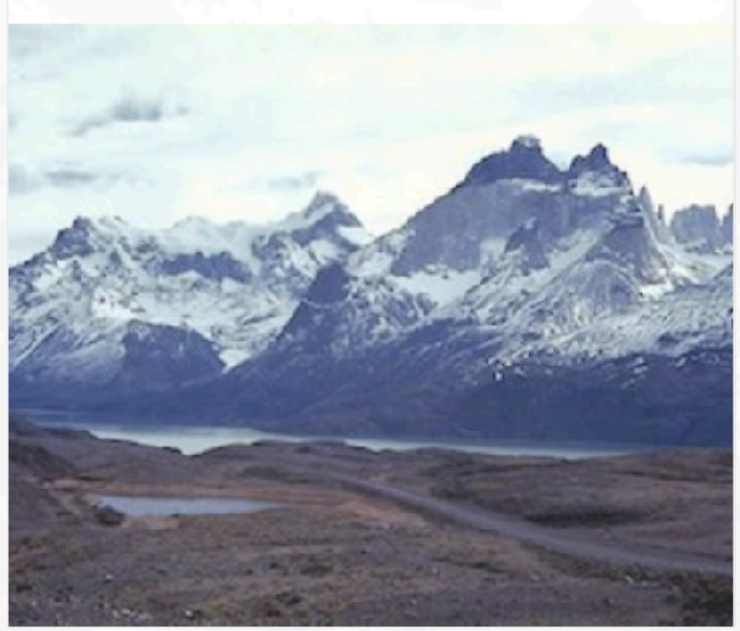

5 What will Earth look like in the future?

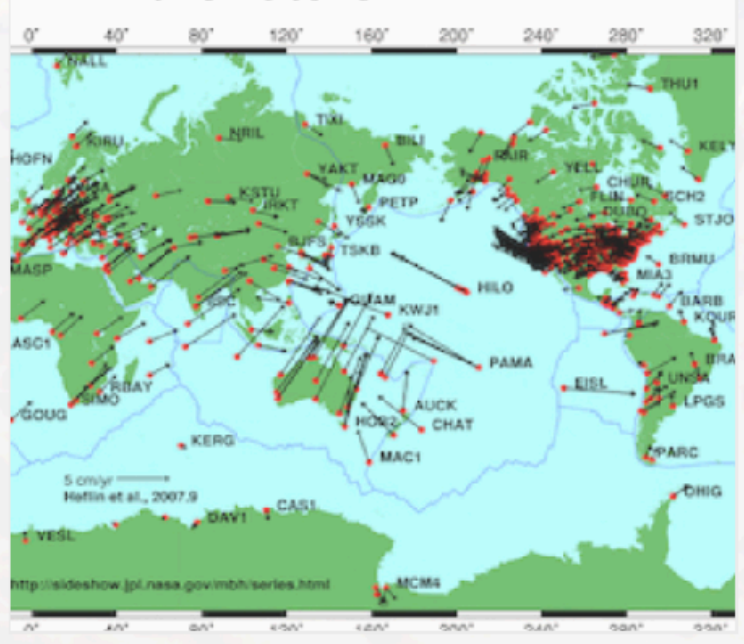

3 What happens with a lot of moving plates?

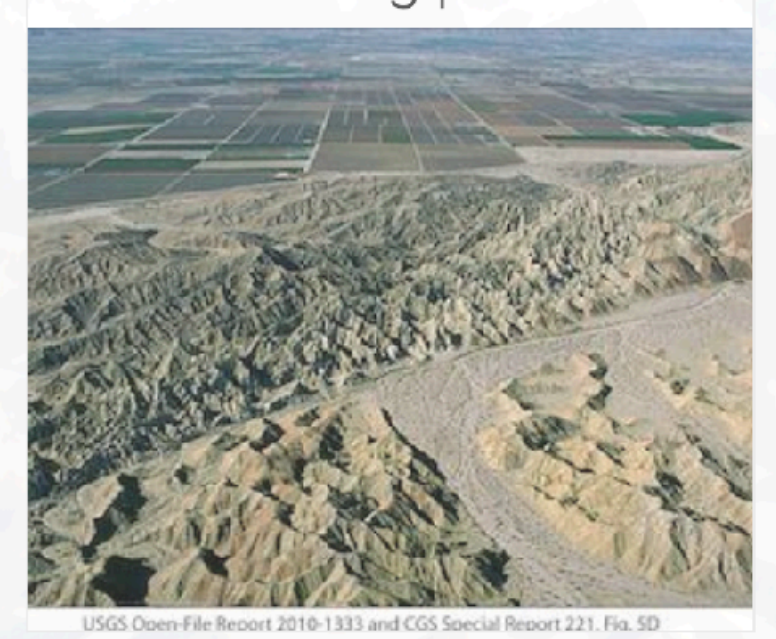

Edit 


\section{Recipe for a GEODE case study}

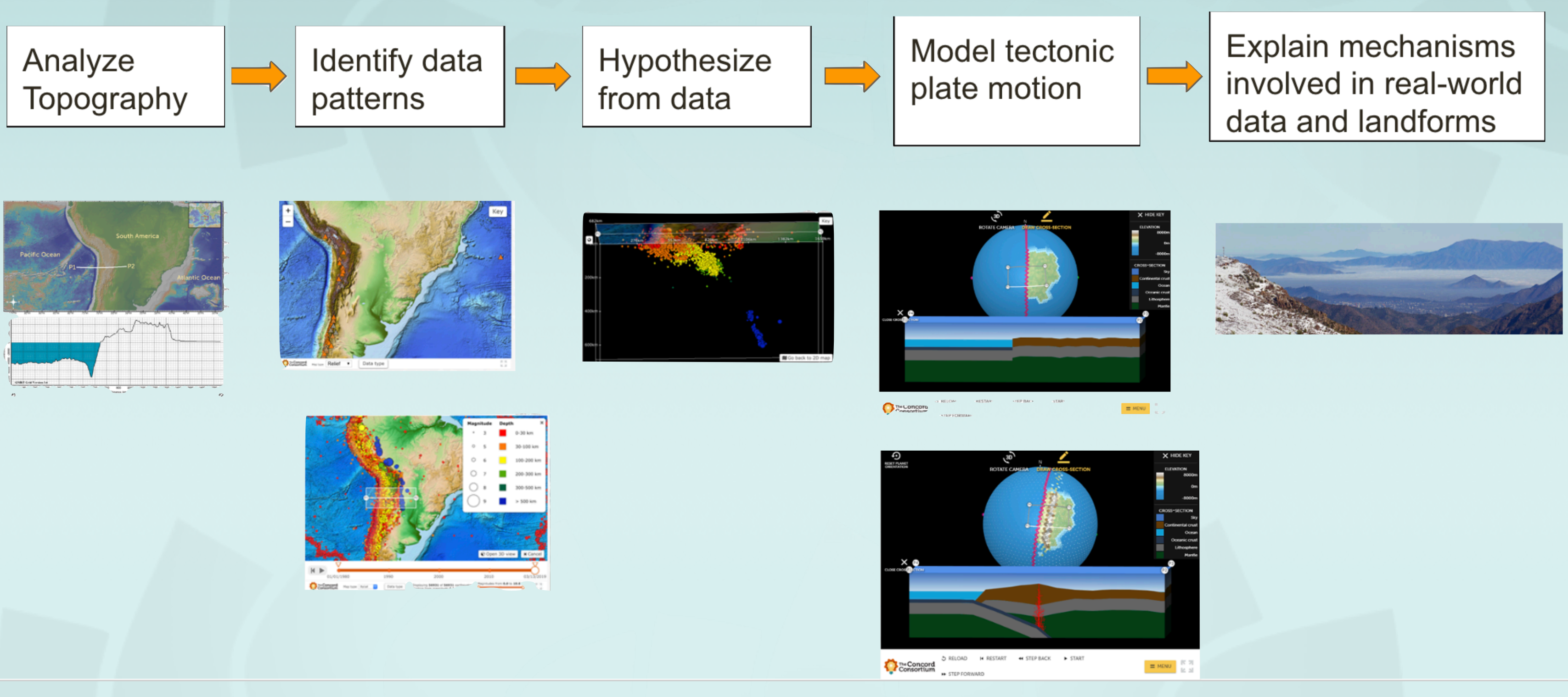




\section{The GEODE Tools}
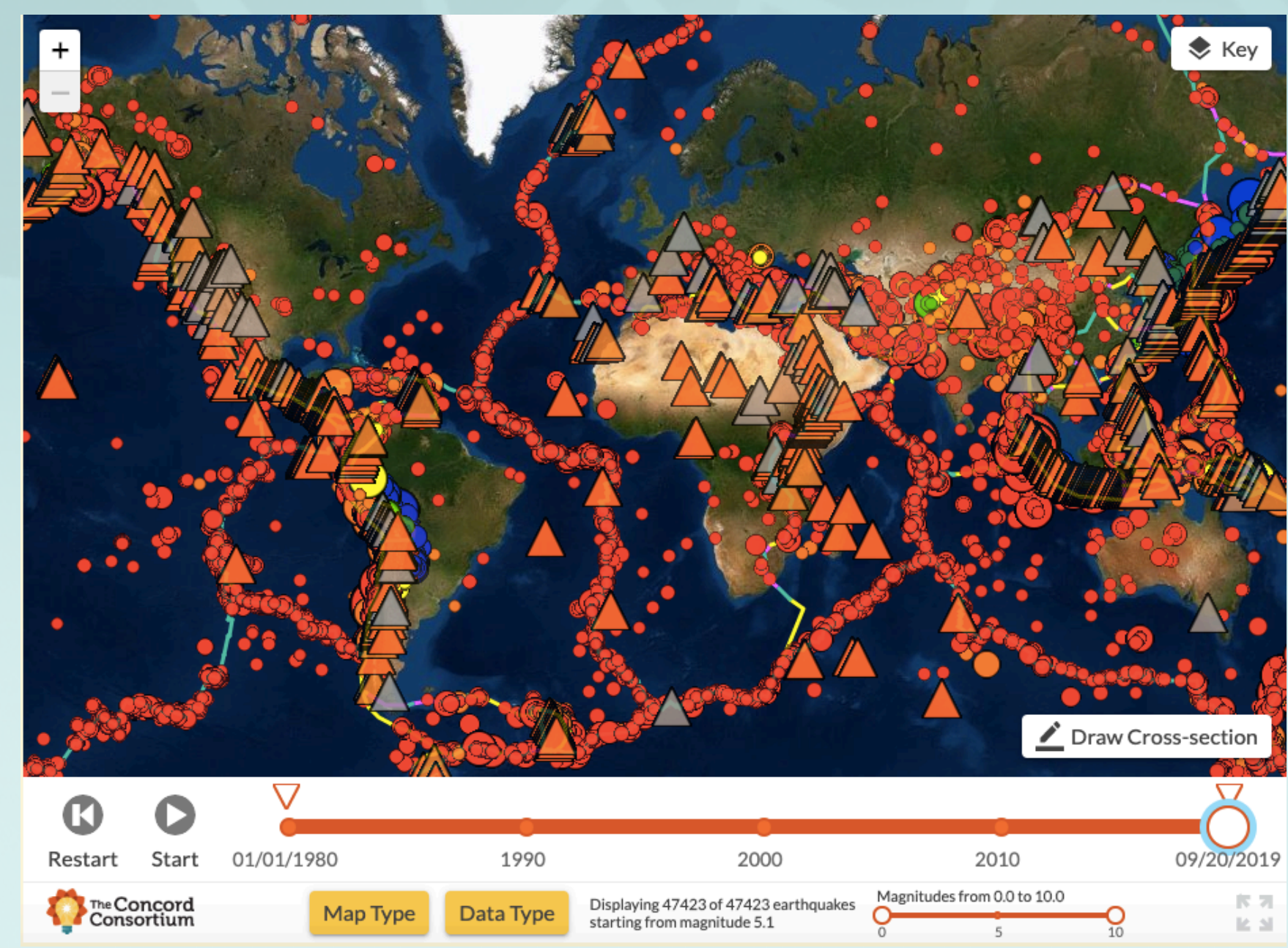

Seismic Explorer can also help students visualize data representing underneath the Earth's surface through cross sections like the one at the right which focuses a section of the Andes Mountains. Students can see that there are increasingly deeper earthquakes moving east, and that volcanoes are above earthquakes at specific depths.

Seismic Explorer uses publicly available data from the USGS in an online data visualization tool which integrates earthquake, volcano and plate motion data sets. Students can select which data to view, and look for patterns in the data.
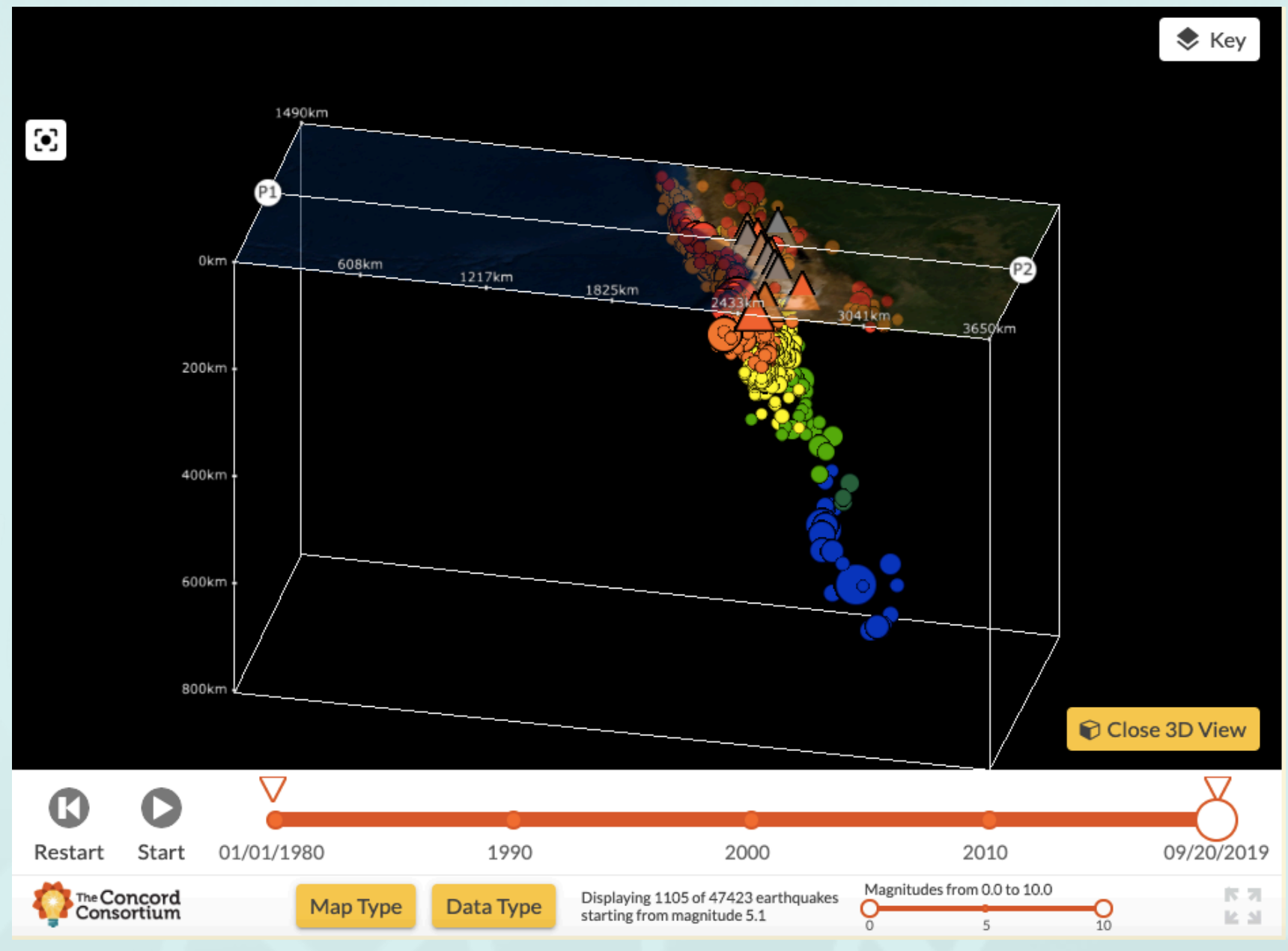


\section{The GEODE Tools}

Tectonic Explorer is an interactive dynamic plate tectonic model of an Earth-like planet which allows students to manipulate the density of plates, number of plates, and direction of forces. Students can also create cross sections to see not only the surface level changes as the plates interact but also the subsurface changes, such as rifts and subduction.
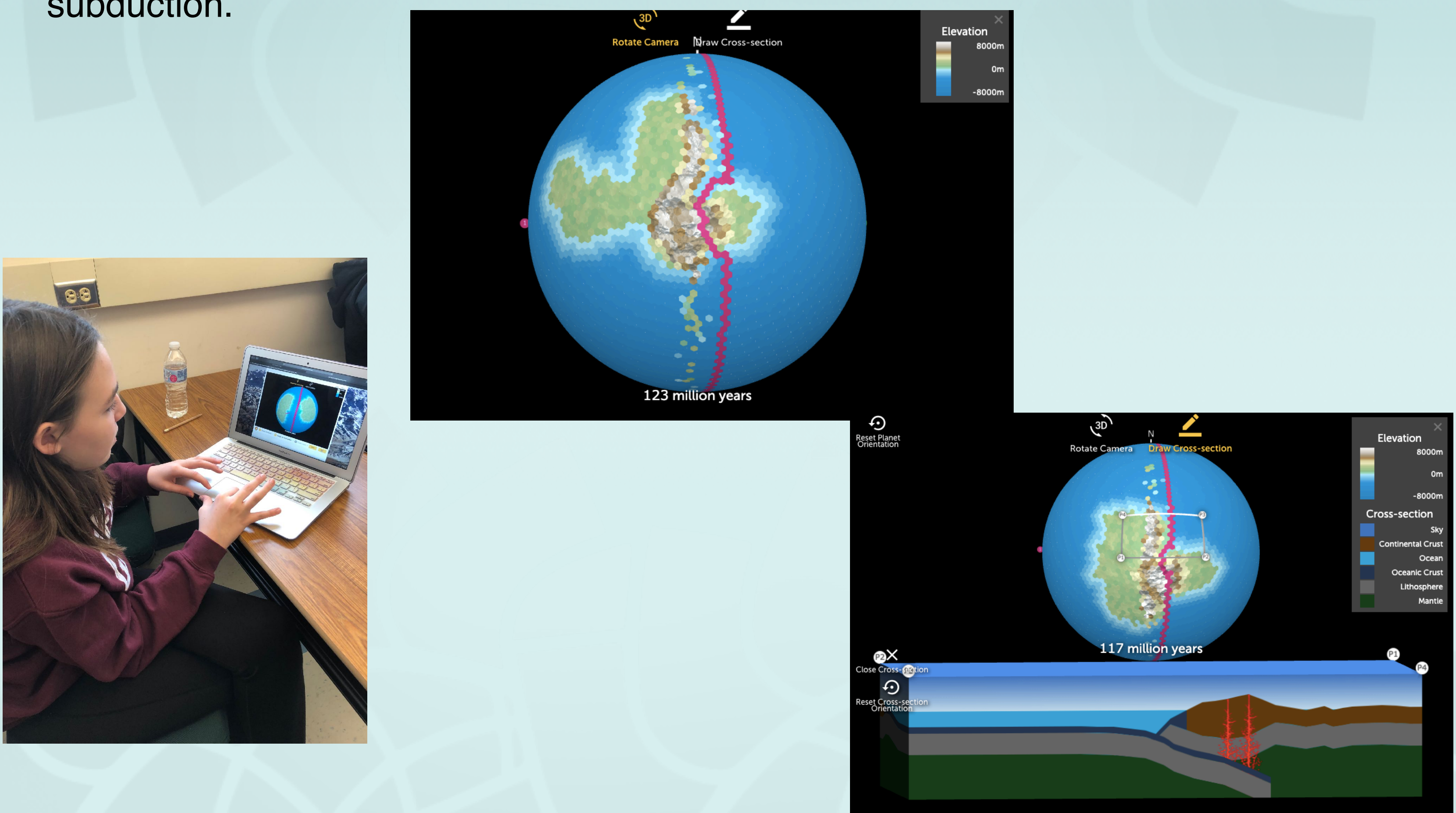


\section{Teacher support material}

\section{Theory \& Background}

This activity is designed around real-world case studies of convergent boundaries. The case studies exploring the formation of the Andes Mountains and the Aleutian Islands follow similar patterns.

First, students look at the distinctive landforms by analyzing geographic profiles. Students then look at earthquake and volcano data associated with these landforms.

After exploring the Andes and Aleutians, students hypothesize about how plate interactions can form areas like the Andes Mountains and the Aleutian Islands. Students then use Tectonic Explorer to test their hypotheses.

The case study later in the activity, exploring the formation of the Himalayan Mountains, requires students transfer what they have learned in the first two case studies to puzzle through a slightly more complex modeling of what occured in that location. (See the Theory and Background tip on page 5 of this activity.)

It is important to help students discover the connections between the real-world data and the motion of plates as they use the tools provided in the activity.

Question \#1
At what point on the geographic profile does the
land elevation rise above sea level?
$670 \mathrm{~km}$
$740 \mathrm{~km}$
$1040 \mathrm{~km}$
Check answer
Students may see an increase from the low point
as being above sea level (670 km) or the highest
point as the point at which sea level is breached
(1040 km).
In each case, direct their attention to the y-axis.
Ask: What elevation represents sea level?
Encourage them to re-read the introduction
before the profile map.

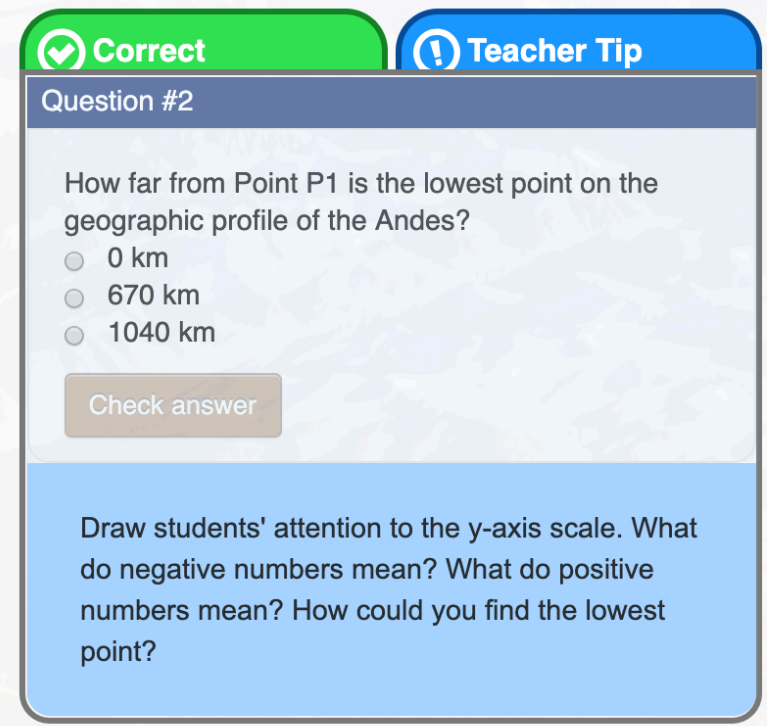

the $y$-axis scale. What do negative numbers mean? What do positive point?

\author{
Alongside the student version \\ of the curriculum, teachers \\ have access to their own \\ specialized version of the \\ curriculum where they can get \\ theory and background about \\ the curriculum, pedagogical \\ supports, exemplar answers \\ and reasoning for acceptable \\ answers in multiple choice \\ questions.
}




\section{PENNSTATE.}

The Concord Consortium

Amy Pallant - Principal Investigator; Concord Consortium Hee-Sun Lee- Co-PI; Concord Consortium

Scott McDonald- Co-PI; Pennsylvania State University

Piotr Janik- Software Developer; Concord Consortium Sarah Pryputniewicz- Curriculum Developer; Concord Consortium Trudi Lord- Project Manager; Concord Consortium

Tanya Furman- Geoscientist; Pennsylvania State University Kevin Furlong- Geoscientist; Pennsylvania State University

Kathryn Bateman- Post-Doctoral Fellow; Temple University

Grant NSF DRL-1621176. 


\section{Questions?}

\section{https://learn.concord.org/geo-platetectonics kathrynbateman@temple.edu}

\section{GEODE}

Explore our free STEM learning resources $\lambda$

Transforming geoscience education with interactive models for exploring plate tectonics.
FOCUS AREA

STEM Models \& Simulations

SUBJECT

Earth \& Space Science

GRADE

Middle School

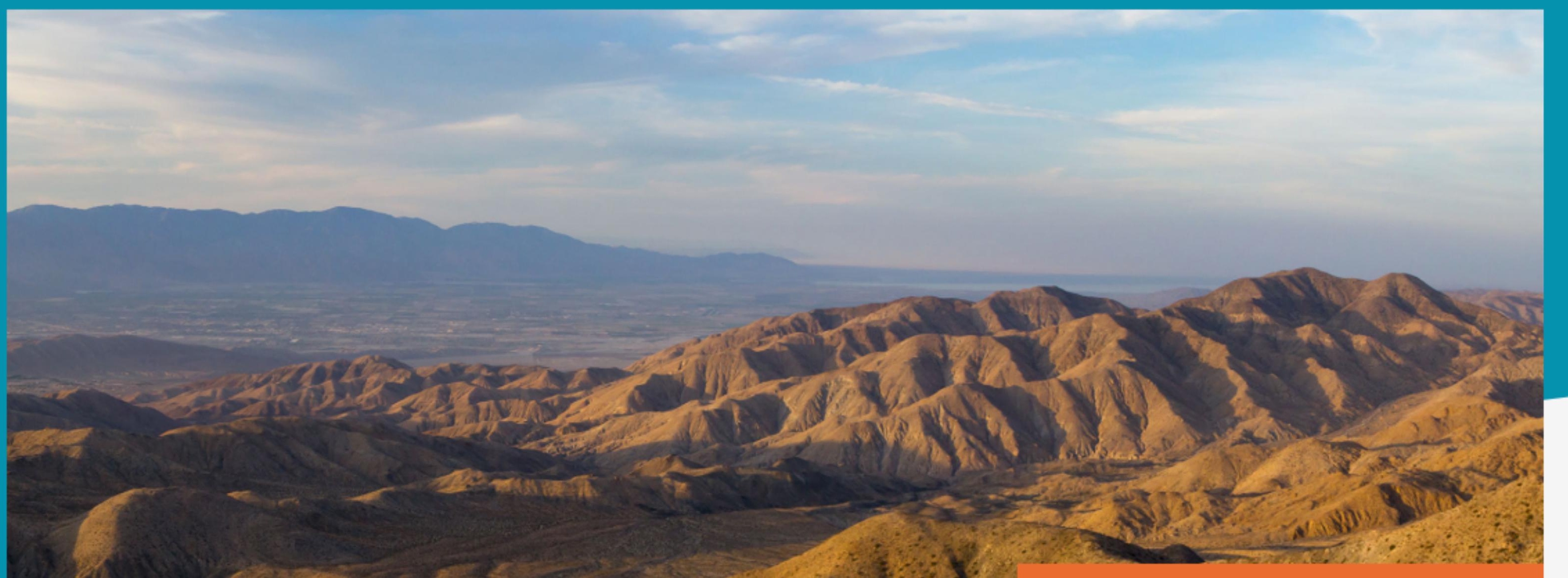

